\title{
The Development of a Satellite Food Pantry Through Community-Based Participatory Action Research
}

Jill Juris

Appalachian State University, USA

Rachel M. Scrivano

The Ohio State University, USA

Elizabeth Speidel

The Ohio State University, USA

Lauren Bailey

The Ohio State University, USA

Shannon E. Jarrott

Appalachian State University, USA

\section{Recommended Citation}

Juris, J., Scrivano, R. M., Speidel, E., Bailey, L., \& Jarrott, S. E. (2021). The development of a satellite food pantry through community-based participatory action research. International Journal of Research on Service-Learning and Community Engagement, 9(1), Article 6. https://doi.org/10.37333/001c.31304 


\section{The Development of a Satellite Food Pantry Through Community-Based Participatory Action Research}

\author{
Jill Juris, Rachel M. Scrivano, Elizabeth \\ Speidel, Lauren Bailey, and \\ Shannon E. Jarrott
}

Food for a Long Life (FFLL) is a communityuniversity-extension project that utilizes intergenerational strategies and a communitybased participatory action research approach to increase healthy food access, consumption, and education for preschoolers and older adults. As a Children, Youth, and Families at Risk sustainable community project of the U.S. Department of Agriculture, FFLL is within its fifth and final year working collaboratively at an intergenerational site in a midwestern United States community identified as being food insecure. During Project Years 2-4, FFLL engaged in iterative communication and relationship-building with stakeholders and a local food bank to identify and address community needs, resulting in the creation of a satellite food pantry. Prior to the COVID-19 pandemic, the Food Satellite served approximately 60 family members each month. FFLL strives for program sustainability beyond the grant-funding period by continuing community partnerships and training staff to facilitate the satellite food pantry operations.

Keywords: community-based participatory action research, food insecurity, food pantry, intergenerational strategies

\section{Desarrollo de una Despensa Satélite de Alimentos a través de la investigación de una acción participativa basada en la omunidad}

\author{
Jill Juris, Rachel M. Scrivano, Elizabeth \\ Speidel, Lauren Bailey, y Shannon E. Jarrott
}

Food for a Long Life (FFLL) es un proyecto de extensión comunitaria-universitaria que utiliza estrategias intergeneracionales y un enfoque de investigación de acción participativa basada en la comunidad para aumentar el acceso a alimentos saludables, su consumo, así como la educación de preescolares y adultos mayores. Como proyecto comunitario sostenible para Niños, Jóvenes y Familias en Riesgo patrocinado por el Departamento de Agricultura de los Estados Unidos, el FFLL se encuentra en su quinto y último año, trabajando en colaboración con un sitio intergeneracional ubicado en una comunidad del Medio Oeste de los Estados Unidos que ha sido identificada como insegura en materia de alimentos. Del segundo al cuarto año del proyecto, el FFLL se dedicó a la comunicación iterativa, fomentando relaciones entre las partes interesadas y un banco de alimentos local con el objetivo de identificar y abordar las necesidades de la comunidad, lo que dio lugar a la creación de una despensa de alimentos. Antes de la pandemia del COVID-19, esta Despensa Satélite de Alimentos atendía a unas 60 personas cada mes. El FFLL se esfuerza por conseguir la sostenibilidad del programa más allá del periodo de financiación de la subvención, continuando con las colaboraciones comunitarias y formando al personal para que facilite el Satélite de Alimentos.

Palabras clave: investigación de acción participativa basada en la comunidad, inseguridad alimentaria, despensa de alimentos, estrategias intergeneracionales

Editors' Note: English-to-Spanish translation by Yamilet Hernandez

Department of English and Foreign Languages

Barry University, USA 


\section{Program Background}

Food for a Long Life (FFLL) is an engaged community-university-extension collaborative project that utilizes intergenerational strategies and a community-based participatory action research (CBPAR) approach to increase healthy food access, consumption, and education for preschoolers and older adults (Jarrott et al., 2019). The FFLL team included university-based researchers as well as a program manager and graduate, undergraduate, and nondegree-seeking students who worked closely with community members (children, families, older adults, and staff) at a shared-site intergenerational center. As a Children, Youth, and Families at Risk sustainable community project of the U.S. Department of Agriculture, FFLL is within its fifth and final grant year, working collaboratively at the community site in the midwestern United States, which was identified as lacking access to healthy foods.

The first year of FFLL was a planning year focused on establishing relationships through a CBPAR approach (Jarrott et al., 2019). Although the project has many facets, this paper highlights only one - efforts made by the FFLL team that includes students to increase healthy food access within one of two project states prior to the COVID-19 pandemic. We describe how the CBPAR approach offered guidance in the development of an innovative program called the "Food Satellite." Working in partnership with a larger food pantry, the Food Satellite allowed families and individuals at an intergenerational shared site (which includes an early learning center and adult day services) to access healthy food from a location that is more convenient to their daily routine than the larger food pantry or food bank.

The community involved at this FFLL site was identified as lacking food security (Jarrott et al., 2019) or being unable to access enough culturally and religiously appropriate food to achieve an active and healthy life (Burchi \& De Muro, 2016; U.S. Department of Agriculture, 2019). Where FFLL operates, 42\% of residents live in poverty (Partners Achieving Community Transformation, 2013), and price is a significant barrier to consumers who wish to purchase fresh produce (Kaiser, 2017). Easy-access convenience stores and corner markets are commonly available in urban, food-insecure areas like this FFLL community, but they rarely sell fresh produce of good quality (Freedman, 2009; Kaiser, 2017). Food insecurity has negative physical and cognitive consequences for youth and older adults (Chang \& Hickman, 2018; Lee \& Frongillo, 2001). With low food security identified as an issue by community partners during the 2016-2017 planning year of FFLL (Jarrott et al., 2019), the focus of subsequent years was on creating sustainable community connections dedicated to providing children and older adults at the FFLL site with increased access to healthy food. To coordinate the shared goal of developing a Food Satellite at the colocated adult and childcare centers, a group of community partners convened, representing families, older adults, staff from the center, a local food bank, university, and extension.

\section{Community-Based Participatory Action Research}

In order to conduct community-engaged research, FFLL implements a CBPAR approach following Israel and colleagues' (2003) nine guiding principles (see Table 1; Jarrott et al., 2019). CBPAR encourages the engagement of both project team members and community members to cocreate during various stages of the research process (Israel et al., 2013), giving rise to the shared voices and responsibilities of those invested in the project goals (Doberneck \& Dann, 2019). In this way, researchers can attempt to enhance mutual learning and build community assets (Minkler \& Baden, 2008) based on common points of interest and participation in a trusting relationship (Lucero et al., 2020). Researchers commonly utilize the CBPAR approach to address health disparities among marginalized community members who share geographic, political, or cultural identities (Minkler \& Baden, 2008; Wallerstein et al., 2013), a central goal of FFLL. Thus, CBPAR provides a strengths-based approach that centers on input from marginalized groups (Israel et al., 2003).

Various studies have found clear indicators of successful CBPAR, such as mutual respect, trust, conflict resolution, knowledge transfer from research to the community, and policy change (Brush et al., 2019). The nine guiding principles proposed by Israel et al. (2003) provided FFLL with a means to achieve impactful community-engaged research. While CBPAR gives researchers opportunity to empower community 
members (Minkler \& Baden, 2008), empowerment theory (e.g., Christens, 2012; Peterson, 2014; Rappaport, 1987) is thought to be a complementary theoretical approach to CBPAR and a prominent theory in person-centered fields like social work (Joseph, 2020). Broadly, empowerment theory is often utilized to foster power and/or authority among community members by providing opportunities for their voices to guide achievement of a particular goal within their environment, resulting in perceived control needed to facilitate community-level change. Efforts to ensure that all voices are heard are often operationalized in stakeholders' conversations.

Table 1

Principles of Community-Based Participatory Research Approach Applied to Food Satellite

\section{CBPAR Principle}

Focuses on local relevance of public health problems and ecological perspectives that attend to multiple determinates of health

Builds on strengths and resources within community Acknowledges community as unit of identity

Facilitates collaborative, equitable partnership in all phases of research, involving empowerment and power sharing that attend to social inequalities

Fosters co-learning and capacity building among partners Involves systems development using a cyclical and iterative process Involves a long-term process and commitment of sustainability

Integrates and achieves balance between knowledge generation and intervention for mutual benefit of partners

Disseminates results to all partners and involves them in wider dissemination of results

\section{Food Satellite Examples}

In regular meetings with both researchers and community members, program manager and students learned about lived experiences of community members and research on similarly situated communities. Program manager and students reflected on how these were interconnected and used them for programming.

FFLL built partnership with food bank director and placed student who knew the community on FFLL team.

Organizers understood that FFLL was a guest entering the community; hired a project manager who was part of the community and, therefore, understood community's culture and dynamics.

Through regular formal and informal meetings among program manager, students, and community members, FFLL built trust, received input, and adjusted communication and programming to meet goals of community.

Continual debriefing sessions with FFLL team with topics such as logistics of implementation and cultural humility.

Frequent communication and debriefing sessions with participants, stakeholders, and FFLL team for improvement towards sustainability.

With sustainability in mind throughout planning and implementation, FFLL worked towards transitioning efforts to onsite staff who participated throughout implementation process.

Students gathered preferences for food distribution through conversations and surveys with families, older adults, and staff during and after food ordering and distribution, combining relationship building and data collection without burdening participants with additional meetings.

Participants returned to Food Satellite and disseminated results to larger food pantry.

In addition to empowerment theory, social support theory (e.g., Jacobson, 1986) is integral for FFLL to disseminate resources to meet the community's needs. As described by Lakey and Scoboria (2005), perceived social support involves both trait and social influences, which in turn influence the mental health of those receiving support. In the current project, FFLL utilizes aspects of social support to reduce burden 
and stress that food-insecure families face by recognizing the importance of both trait and social influences. Following the CBPAR approach (Israel et al., 2003), FFLL continually obtains informational support from knowledgeable project partners, which contributes to the project's ability to provide tangible support to families in the form of food resources. In this way, social support is seen as an interpersonal process with a focus on the ability of community members to thrive (Feeney \& Collins, 2015). Thus, social support guides the facilitated "action" piece in CBPAR through different phases of the Food Satellite. The use of a CBPAR approach coupled with empowerment theory and aspects of social support theory is appropriate for FFLL and the Food Satellite, given the community of focus, needs to be addressed, and desire to invest private citizens and organizations in a sustainable partnership.

\section{Community Partnerships}

In tandem with a CBPAR approach, community partnerships allow for a bridge from theory to practice. With a focus on creating and implementing a Food Satellite in a location where the community identified a need, FFLL focused efforts to connect community partners, university representatives, and extension staff. Doberneck and Dann (2019) provide the Degree of Collaboration Abacus Tool to visually represent voice and authority throughout the community engagement process. We present a modified version of this tool in Table 2, which depicts our roles throughout the implementation process of this food satellite food project.

In this project, the community partners included the director of a local food bank, director of a childcare center, and the director of an adult daycare center. The university partners included two intergenerational program scholars, a Ph.D. in social work student, and service-learning students. The community liaisons played a critical role between the community partners and university team. The community liaisons were the FFLL onsite program manager, Master of Social Work (MSW) student, and extension educator. The FFLL onsite program manager and MSW student figured centrally in this effort as they were uniquely situated between the university team, participated in regular FFLL meetings, and were housed onsite in the colocated child and adult day services building to establish necessary relationships with community partners, families, children, and older adults. They also served as liaisons to the service-learning students during the Food Satellite implementation. The extension staff was a family and consumer sciences educator specializing in nutrition, who collaborated with community partners and the university team.

By partnering with the extension system and a local university, FFLL focused on sustainability of the Food Satellite to ensure its continuation beyond the grant-funding period. The extension system provides a nationwide network by which research conducted or reviewed by specialists at the land-grant and affiliated universities is shared with community members in practical, easy-to-follow language through extension agents or educators who offer in-person training demonstrations, develop online and print materials, and host webinars. While the extension system is frequently associated with care of crops and animals, FFLL worked with county extension educators in the areas of nutrition and family and consumer science. The project's connection to the county extension offices enhances the Food Satellite's sustainability; educators can work with the partnering organizations beyond the grant-funding period as part of their extension mission. This may be done, for example, by convening local stakeholders in nutrition and food security issues or by offering education and informational resources to Food Satellite staff and participants. Involvement with extension can also support scaling up the Food Satellite, as extension specialists and educators can disseminate program development and implementation plans to wider audiences interested in establishing their own Food Satellite, something that staff delivering the Food Satellite may be unable to do due to lack time and other resources. Forming partnerships is a precursor and an ongoing necessity in CBPAR efforts (see Figure 1); university and extension partnerships are critical in the current project.

In the next section, we illustrate how CBPAR was employed in the Food Satellite effort. We share information specifically on assessing the community and strengthening the partnerships as well as the defining the issue and formulating a central research question 
Table 2

Food for a Long Life's Food Satellite Implementation Abacus

\begin{tabular}{|l|l|l|}
\hline Steps in CE Project & $\begin{array}{c}\text { Community } \\
\text { Partners }\end{array}$ & $\begin{array}{c}\text { Community } \\
\text { Liaisons }\end{array}$ \\
\hline $\begin{array}{l}\text { Determined community } \\
\text { need for easier access to } \\
\text { healthy food }\end{array}$ \\
\hline $\begin{array}{l}\text { Researched food pantry } \\
\text { operation }\end{array}$ \\
$\begin{array}{l}\text { Determined research } \\
\text { question focused on } \\
\text { sustainability of Food } \\
\text { Satellite }\end{array}$ \\
\hline $\begin{array}{l}\text { Implemented Food } \\
\text { Satellite }\end{array}$ \\
$\begin{array}{l}\text { Conducted iterative } \\
\text { debriefing and } \\
\text { observations }\end{array}$ \\
\hline $\begin{array}{l}\text { Communicated with } \\
\text { stakeholders for } \\
\text { sustainability of Food } \\
\text { Satellite }\end{array}$ \\
$\begin{array}{l}\text { Transition partnerships to } \\
\text { on-site staff for sustained } \\
\text { program }\end{array}$
\end{tabular}

\section{Assessing the Community and Strengthening the Partnerships}

\section{Listening to Community Feedback to Identify a Need}

Forming partnerships and assessing community resources and needs continued beyond the first planning year (Jarrott et al., 2019). The impetus for creating a Food Satellite came after two years of FFLL programming involving classroom education and distribution of fresh vegetables through a communitysupported agriculture program. Feedback from parents and older adults about the value of sending fresh produce home with families was complemented by input from site staff (Jarrott et al., in press) that a Food Satellite would support the project's commitment to increase healthy food access and consumption (Jarrott et al., 2019). During Year 3 of FFLL, an administrator from the childcare center introduced the idea of leveraging its relationship with a local food pantry to bring a satellite food pantry to the site. The larger pantry was rarely used by families of the childcare center because it was challenging for families to access the pantry to pick up food when it was open, particularly when collecting groceries with their young children. Older adults affiliated with the site would depend on family caregivers to access the larger pantry. For these reasons, the FFLL team believed that the satellite food pantry could increase access to healthy 
food for staff and families at both the childcare and adult-care centers. Eight months of conversations (January-August 2019) with community partners from the pantry and the child- and adult-care centers followed, with stakeholders discussing what a Food Satellite could look like and whether it would be utilized by families and staff at this site.

\section{Engaging in Community Conversations to Determine Logistics of Implementation}

In order to develop the Food Satellite, we used a CBPAR strategy that included conversations within the community to initiate planning. FFLL team members began considering the logistical issues of establishing a satellite food pantry by contacting other food pantries to gain insight on their operations that could inform our community discussions. Then, following the CBPAR approach, the onsite FFLL program manager consulted with community stakeholders at the site, families, and staff throughout the development stages of the Food Satellite. In addition to administration and staff, the program manager had individual conversations with older adults and parents to determine the following: the utility of the Food Satellite, including the amount of food desired and specifics of transporting food home; whether a Food Satellite would be valuable to them; and what aspects of a Food Satellite (e.g., food ordering and distribution methods and the importance of choice, speed, and/or privacy) would be vital for program success. Once need, interest, and requirements were established, the program manager met with a local food pantry that had a relationship with the preschool. Meeting with the local food pantry director allowed for an initial collaborative relationship to learn how the Food Satellite could work in conjunction with programs already in existence. Moreover, this meeting resulted in a field placement opportunity for a social work graduate student. The student, with support from the program manager, identified steps for three phases of the Food Satellite: ordering food, receiving food, and food distribution. Then social work graduate and undergraduate students implemented the Food Satellite, with support from the program manager, for seven months prior to the onset of COVID-19, which caused closures of the sites. After each Food Satellite project was implemented, the program manager and graduate student provided debriefs to the larger FFLL team.

\section{Defining the Issue and Formulating a Central Research Question}

FFLL aims to deliver sustainable programming to increase healthy food access and consumption among children, older adults, and their families living in areas lacking food security. Therefore, the guiding research question for the Food Satellite was as follows: "How does FFLL prepare a community-operated healthy food access initiative to meet community need beyond a grant funding period?" To operationalize this primary issue and effort, all decisions in the process of implementing a Food Satellite through a CBPAR approach were guided by the question, "Is this sustainable?" Below, we describe the processes involved in the development and implementation of the Food Satellite as viewed through the lens of nine CBPAR principles.

\section{Implementation of the Food Satellite}

There are nine CBPAR principles in Israel and colleagues' guidelines (2003), each of which played an integral part in the Food Satellite implementation (see Table 1). We will now highlight and describe how FFLL utilized CBPAR principles from four areas central to the implementation of the Food Satellite.

\section{Building Collaborative Relationships}

\section{Building on Strengths and Resources Within the Community}

The most valuable resource of this project has been the people onsite and the strength of the collaborative engagement that has taken place among key stakeholders. The strong partnership between the childcare center and a local food pantry served as the foundation of the Food Satellite. These relationships illustrated the CBPAR principle that research builds on strengths and resources within the community. The pantry director connected the site to the food and ordering system and provided essential training on 
completing required paperwork, the online ordering and delivery platforms, and setting up the physical space. Staff members, families, older adults, and students at the site were central to the iterative process needed to respond to challenges and mistakes and to recognize accomplishments during each stage of the project.

\section{Acknowledging This Community as a Unit of Identity}

Two other strengths of collaborative engagement and relationships are the partners' trusted network of communication and a shared history of facing and overcoming challenges to achieve positive outcomes for participants (i.e., families, children, and older adults). Acknowledging this community as a unit of identity with these strengths informed how FFLL engaged with partners. The communication network and shared history allowed FFLL to identify an appropriate location for Food Satellite operations, such as space to house materials like the grant-funded refrigerator, freezer, and shelving units for food storage and semiprivate space for Food Satellite workers to distribute food to participants without impacting concurrent activities in the shared space. FFLL also utilized university resources and community connections unique to the colocated centers.

\section{Communicating Throughout the Implementation Process}

Aligned with CBPAR and community engagement approaches, FFLL incorporated enabling mechanisms of communication identified for successful interventions (De Weger et al., 2018). By strengthening relationships with families of children at the childcare site and older adults at the adult day center, FFLL team members spent time with them during the ordering and distribution process. Communication during implementation started with sitting with participants and identifying what they needed to successfully place their order. After all orders were placed, the program manager communicated with the food pantry partner to verify that all orders were received. The pantry partner delivered all ordered food, which staff and students then consolidated into packaging for each family. Prior to food distribution days, reminders were given to parents and staff. Staff and students began giving the director and teachers of the childcare center and frontline staff of the adult day center a list of participating families on food distribution days, which allowed another set of people to remind individuals to gather their food when preparing to leave. Informal, direct feedback from participants allowed the pantry process to evolve from month to month in order to best fit participants' needs (McDavitt et al., 2016).

\section{Facilitating a Collaborative, Equitable Partnership}

Any attempt to cocreate a collaborative, equitable partnership is rooted in communication techniques that allow each partner to be heard, understood, and answered. At its most elemental level, this requires time and space in which people can participate. Furthermore, individuals must acknowledge and respond to the realities under which each partner operates. The intergenerational center's community partners, like many early childhood care and adult day providers, have limited time. FFLL aimed to support community partners' commitment to those they serve while operating with time constraints. Therefore, FFLL needed to identify ways to establish flexible, consistent, and effective communication without sit-down group meetings at fixed times and to continually communicate progress towards shared goals. As a result, most communication occurred as one-on-one conversations when people were "free," often in the hallways or lobby (McDavitt et al., 2016). The onsite program manager and students would meet with onsite program contacts to ask questions, identify solutions, and provide updates.

Similar to program staff, childcare families participating in the Food Satellite are often pressed for time. The program manager and students had brief meetings with the families before they picked up their children and communicated reminders via text messages and flyers. Communicating with older adults was easier because they were present at the center all day long. These varied styles of communication may not have been the most efficient for the onsite program manager and students. However, they were the most effective ways to ensure that participants received and understood communications and had opportunities to offer 
input. This flexible approach was also consistent with how the organizations communicated internally. CBPAR, when done well, requires project partners to enter the community's world. This approach has contributed to the successes seen during the FFLL project thus far.

\section{Fostering Co-learning and Capacity Building Among Partners}

The Food Satellite engaged students in service-learning rooted in co-learning and capacity building (Israel et al., 2003). The students were integrated into all aspects of the Food Satellite, and their participation was pivotal to success of the inaugural year. One way that students benefited from this program was by maintaining consistent involvement with a project that encouraged dialogue between a wide range of audiences. Students were able to remain involved with the project for an extended period, allowing relationships to develop organically over months. Reciprocal exchange of diverse skills among participants, staff, and other students resulted. Diverse skills were also associated with diverse student responsibilities, which created some challenges when scheduling student support of the Food Satellite. However, as the program evolved, the number of participating students increased, which minimized the challenge of accommodating varied schedules and diversified perspectives. In all, students who contributed to the development of the Food Satellite built skills related to operating a largescale program while working alongside members of the community who have lots to share, and whose expertise was critical to the success of the project.

\section{Debriefing Sessions and Observations}

\section{Utilizing a Cyclical and Iterative Process}

Following the CBPAR principle of utilizing a cyclical and iterative process, debriefing sessions held during the early months of operation proved important for the Food Satellite's success (see Figure 1). Debriefing sessions took place during food ordering and distribution with participating families, older adult participants, and key stakeholders. These conversations allowed us to discern aspects of our process that were helpful or could be improved upon to make the Food Satellite more effective and sustainable. Debriefing sessions allowed us to make several adaptations to our process. One important adaption related to the efficiency of food distribution for all age groups. Initially, participants could freely select produce during pickup; however, through conversations with participants and service-learning students assisting with the satellite food project, the FFLL team learned that families preferred prepackaged produce based on family size.

Partnering with a multigenerational site, FFLL focused on meeting the needs and engaging the interests of multiple age groups, which required an iterative, responsive process of observation and engagement around Food Satellite operations. Considering the children's families first, FFLL used a method of distribution that involved meeting families at their vehicle with their orders. Through observation and conversation, FFLL team members discovered that most participating families preferred signing for their food before picking up their child from the classroom. Staff and students then gathered and positioned items while the parent/guardian collected their child and drove their car to the loading location at the back of the building.

Regarding the older adult participants, food distribution differed as these participants relied primarily on a driving service to get home from the adult day program. While some adults could help to transport their order to and from the car, others could not. Physical difficulty carrying the order from the car into her home led one participant to decline placing a subsequent order from the Food Satellite. When the onsite program manager learned through conversation with the participant why she had not placed an order, arrangements were made for her to break up the order and carry it home over two days. Recognizing that parents without access to a personal vehicle as well as older adults living alone might face a similar issue of transporting food, participants were invited to split the order for pickup over two days, which allowed a number of participants to join or continue in the program. Finally, because Food Satellite participants have ever-changing schedules, the FFLL team determined that inflexible operating hours were limiting. Through 
informal conversations, FFLL team members learned that some parents were unable to gather their items on the initial distribution day because they were picking up their children before the Food Satellite began distributing orders. Adjusting operating hours ensured that the Food Satellite overlapped with the pickup times for all participants.

\section{Establishing a Long-Term Process and Commitment to Sustainability}

One of the most successful modifications made to the distribution process was the use of a checklist developed by students. Initially, university students and the program manager were solely responsible for food distribution so as to avoid placing additional burden on child- and adult-care staff and to allow maximum flexibility for families. However, when food distribution lasted over a week, rather than a day or two as originally planned, FFLL thought to integrate partners in the work to increase sustainability efforts. As part of the long-term process and commitment to sustainability, FFLL identified site staff (childcare teachers and administration, adult day receptionist, and activities staff) who could assist in food distribution, particularly when university students and project staff were not present at the site. Teachers were able to collect the food for their children's families (which was packed and ready for pickup) after the first two distribution days. When needed, the adult day staff collected food and distributed it to older adults when they left for the day. The ability of partners to provide this support ensured that everyone received their order, even if they had been absent or unable to pick it up on the day of the Food Satellite operation. The additional work for teachers and staff was minimal and provided the foundation for the partners to continue the Food Satellite beyond grant funding. Adaptations such as these, identified through debriefing sessions organized among Food Satellite team members with participants, were vital for improving the process for all involved.

Across the seven months the Food Satellite has been operating, food has been distributed to 426 people representing 33 households. Eight households ordered food from the Food Satellite all seven months. The individuals who placed orders represent, on average, 60 individuals from children's families, older adults, and staff. Approximately 20 orders were placed each month (September 2019-March 2020) for a total of about 140 orders. Repeated orders are placed primarily by parents of children enrolled at the center (53 of the total orders), followed by staff (49 of the total orders), and older adults ( 40 of the total orders). To qualify for the Food Satellite, participants self-identified as meeting the income guidelines used by the food pantry partner.

\section{Making a Long-Term Commitment}

FFLL learned many lessons from this project, each reflecting the principle that CBPAR involves a longterm process and commitment to sustainability (Israel et al., 2003). The Food Satellite grew out of a longterm process necessary to create relationships among partners, which was strengthened by reciprocity and respect for each other. Furthermore, one way to build commitment is to ensure a collaborative, equitable partnership at every step. To achieve equitable presence, the university used its resources (students, staff, and financial support) so that each stakeholder (staff, families, older adults, and administration) was heard, understood, and incorporated into the project. Trusting the shared identification of needs and resources (Jarrott et al., in press), stakeholders engaged in the time-intensive, iterative process of creating a system that fit the community, reflecting another CBPAR principle (Israel et al., 2003). By initiating the Food Satellite with a small number of participants, the FFLL team was able to respond to challenges while also growing the number of participants over time, from 18 to 54. In this way, stakeholders cocreated a system to respond to participants rather than build a system to which participants would need to respond. Finally, the community exhibited compassion and grace when tasks took longer than expected and mistakes in orders were made. The most powerful lesson learned in cocreating a community project is that when researchers are fully committed to community members in a way that acknowledges their value as builders and leaders, there is no shortage of compassion. 


\section{Discussion and Next Steps}

Communication with project partners was one of the most important aspects of this community-level effort. Communication facilitated each of the highlighted CBPAR components (Israel et al., 2003), enabling all project members to produce a successful satellite food pantry to provide food-insecure families with increased access to healthy food at a convenient location. However, this project would not have been possible without initial conversations held with site stakeholders. Communication among stakeholders is central to the CBPAR approach (Israel et al., 2013; Minkler \& Baden, 2008). Aspects of empowerment theory (Christens, 2012; Peterson, 2014; Rappaport, 1987) within the CBPAR process (Israel et al., 2003) allowed stakeholders to communicate ideas enabling FFLL to provide tangible social support (Jacobson, 1986) for involved families through the production of the satellite food pantry. First, though, members of the FFLL team were provided with informational support (Jacobson, 1986) through communications with stakeholders and training with food pantry experts. Importantly, CBPAR (Israel et al., 2003) lends itself to equitable collaboration with community members impacted by community programming, allowing affected participants to voice comments and concerns (Christens, 2012; Peterson, 2014; Rappaport, 1987). These perspectives resulted in necessary changes to further improve the satellite food pantry and its process to accommodate communicated needs.

Clear communication depends on trust between university and community partners (Lucero et al., 2020). Trusting relationships build successful partnerships in long-standing, community-level projects (Brush et al., 2019). Building trust takes time (Orphan et al., 2018); partners must accommodate one another's needs and schedules. Within the current project, trust was established in the planning period and strengthened throughout implementation by ongoing conversations among community, university, and stakeholder partners. Such trust enabled partners working at the site to conquer challenges and serve families in need. It was also important to establish trust with participants of the Food Satellite. Diverse partners simultaneously shared unique skills, knowledge, and experience, which fostered trust and contributed to goal achievement (Brush et al., 2019). Trust is critical; it fosters flexibility and adaptability needed within projects, especially during transitional periods, such as when partners allocate resources for project continuation (Brush et al., 2019).

Throughout this project, the mutual trust that was established allowed FFLL to adapt and be flexible, advancing the project towards sustainability. CBPAR offers a range of benefits; however, the approach also poses specific challenges. For instance, tension may arise between partner groups related to prioritizing multiple commitments held by community partners, university, personnel, and other stakeholders (Wilson et al., 2018). COVID-19 presents challenges to CBPR projects with many shifting to virtual protocols (Valdez \& Gubrium, 2020). The trusted relationships and communication between the community liaisons, community partners, and the university team allowed FFLL to shift operations to continue meeting community needs. The current pandemic paused the Food Satellite due to the closure of centers. However, insights from community partners informed adaptations as FFLL transitioned the satellite food pantry operations to community stakeholders through remote food delivery until the centers are fully open again after COVID-19 (English et al., 2021). This agility based on communication and relationships provides insight for handling future times of crisis. Although data collection plans were adjusted because of COVID19, future data collection on a project such as the Food Satellite could include questions related to food matching participants' cultural diet and health indicators connected to consumption of fresh fruits and vegetables before and after participating in the project.

\section{Conclusion}

Taking a CBPAR approach, FFLL integrated the community's goals through an iterative process to develop a Food Satellite that aimed to increase access to healthy food for families at colocated childcare and adult day centers. With a goal of sustainability beyond the grant-funding period, CBPAR provided the framework for FFLL to focus on building collaborative relationships, communicating, and continually debriefing with patience and compassion to meet all stakeholders' goals. Lessons learned throughout the implementation 
process informed the progression of the Food Satellite, and efforts continue to be made in moving community partner relationships towards program sustainability.

\section{References}

Burchi, F., \& De Muro, P. (2016). From food availability to nutritional capabilities: Advancing food security analysis. Food Policy, 60, 10-19. https://doi.org/10.1016/j.foodpol.2015.03.008

Brush, B. L., Mentz, G., Jensen, M., Jacobs, B., Saylor, K. M., Rowe, Z., Israel, B. A., \& Lachance, L. (2019). Success in long-standing community-based participatory research (CBPR) partnerships: A scoping literature review. Health Education \& Behavior, 47(4), 556-568. https://doi.org/10.1177\%2F1090198119882989

Chang, Y., \& Hickman, H. (2018). Food insecurity and perceived diet quality among low-income older Americans with functional limitations. Journal of Nutrition Education and Behavior, 50(5), 476484. https://doi.org/10.1016/j.jneb.2017.09.006

Christens, B. D. (2012). Toward relational empowerment. American Journal of Community Psychology, 50(1-2), 114-128. https://doi.org/10.1007/s10464-011-9483-5

De Weger, E., Van Vooren, N., Luijkx, K. G., Baan, C. A., \& Drewes, H. W. (2018). Achieving successful community engagement: A rapid realist review. BMC Health Services Research, 18(1). https://doi.org/10.1186/s12913-018-3090-1

Doberneck, D. M., \& Dann, S. L. (2019). The degree of collaboration abacus tool. Journal of Higher Education Outreach and Engagement, 23(2), 93-107.

English, E., Long, C. R., Langston, K., Faitak, B., Brown, A. L., Echegoyen, A., \& McElfish, P. A. (2021). A community partnership for home delivery of food boxes to COVID-19 quarantined and isolated families. Journal of Hunger \& Environmental Nutrition, 16(1), 19-28. https://doi.org/10.1080/19320248.2020.1863284

Feeney, B. C., \& Collins, N. L. (2015). A new look at social support: A theoretical perspective on thriving through relationships. Personality and Social Psychology Review, 19(2), 113-147. https://doi.org/10.1177/1088868314544222

Freedman, D. A. (2009). Local food environments: They're all stocked differently. American Journal of Community Psychology, 44, 382-393. https://doi.org/10.1007/s10464-009-9272-6

Israel, B. A., Eng, E., Schulz, A. J., \& Parker, E. A. (2013). Introduction to methods for CBPR for health. In B. A. Israel, E. Eng, A. J. Schulz, \& E. A. Parker (Eds.), Methods for community-based participatory action research for health (pp. 3-37). Jossey-Bass.

Israel, B. A., Schulz, A. J., Parker, E. A., Becker, A. B., \& Guzman, A. A. (2003). Critical issues in developing and following community-based participatory research principles. In M. Minkler \& N. Wallerstein (Eds.), Community-based participatory research for health (pp. 56-73). Jossey-Bass.

Jacobson, D. E. (1986). Types and timing of social support. Journal of Health and Social Behavior, 27(3), 250-264.

Jarrott, S. E., Cao, Q., Dabelko-Schoeny, H. I., \& Kaiser, M. L. (2019). Developing intergenerational interventions to address food insecurity among pre-school children: A community-based participatory approach. Journal of Hunger \& Environmental Nutrition, 1-17.

https://doi.org/10.1080/19320248.2019.1640827 
Jarrott, S. E., Juckett, L. A., Naar, J. J., Scrivano, R. M., \& Lobb, J. M. (in press). Addressing children's nutritional needs with community-based participatory action research: Staff reflections. Health Promotion Practice.

Joseph, R. (2020). The theory of empowerment: A critical analysis with the theory evaluation scale. Journal of Human Behavior in the Social Environment, 30(2), 138157. https://doi.org/10.1080/10911359.2019.1660294

Kaiser, M. L. (2017). Redefining food security in a community context: An exploration of community food security indicators and social worker roles in community food strategies. Journal of Community Practice, 25(2), 213-234. https://doi.org/10.1080/10705422.2017.1308897

Lakey, B., \& Scoboria, A. (2005). The relative contribution of trait and social influences to the links among perceived social support, affect, and self-esteem. Journal of Personality, 73(2), 361-388. https://doi.org/10.1111/j.1467-6494.2005.00312.x

Lee, J. S., \& Frongillo, E. A., Jr. (2001). Nutritional and health consequences are associated with food insecurity among US elderly persons. The Journal of Nutrition, 131(5), 1503-1509. https://doi.org/10.1093/jn/131.5.1503

Lucero, J. E., Boursaw, B., Eder, M. M., Greene-Moton, E., Wallerstein, N., \& Oetzel, J. G. (2020). Engage for equity: The role of trust and synergy in community-based participatory research. Health Education \& Behavior, 47(3), 372-379. https://doi.org/10.1177\%2F1090198120918838

McDavitt, B., Bogart, L. M., Mutchler, M. G., Wagner, G. J., Green Jr, H. D., Lawrence, S. J., Mutepfa K. D., \& Nogg, K. A. (2016). Dissemination as dialogue: Building trust and sharing research findings through community engagement. Preventing Chronic Disease, 13. https://doi.org/10.5888/pcd13.150473

Minkler, M., \& Baden, A. (2008). Impacts of CBRP on academic researchers, research quality and methodology, and power relations. In M. Minkler \& N. Wallerstein (Eds.), Community-based participatory research for health: From process to outcomes (2nd ed., pp. 243-262). JosseyBass.

Orphan, C., Romero, D., \& Diaz-Solodukhin, L. (2018). Fostering collective impact: Measuring and advancing higher education's contributions to civic health and equity in Colorado. International Journal of Research on Service-Learning and Community Engagement, 6(1), Article 5. https://ijrslce.scholasticahq.com/article/6981

Partners Achieving Community Transformation. (2013). Columbus Near East Side: Blueprint for community investment.

https://static1.squarespace.com/static/5abcf63ce7494052bf25061d/t/5ac235dd0e2e721df048f8f8/ 1522677243294/Blueprint-for-Community-Investment_July-10-2013.pdf

Peterson, N. A. (2014). Empowerment theory: Clarifying the nature of higher-order multidimensional constructs. American Journal of Community Psychology, 53(1-2), 96-108. https://doi.org/10.1007/s10464-013-9624-0

Rappaport, J. (1987). Terms of empowerment/exemplars of prevention: Toward a theory for community psychology. American Journal of Community Psychology, 15(2), 121-148. https://doi.org/10.1007/BF00919275

U.S. Department of Agriculture. (2019). Definitions of food security. https://www.ers.usda.gov/topics/food-nutrition-assistance/food-security-in-the-us/definitions-offood-security.aspx 
Valdez, E. S., \& Gubrium, A. (2020). Shifting to virtual CBPR protocols in the time of Corona Virus/COVID-19. International Journal of Qualitative Methods, 19, https://doi.org/10.1177\%2F1609406920977315

Wallerstein N., Duran B., Minkler, M., \& Foley K. (2013). Developing and maintaining partnerships with communities. In B. A. Israel, E. Eng, A. J. Schulz, \& E. A. Parker (Eds.) Methods for communitybased participatory research for health (2nd ed., pp. 31-51). Jossey-Bass.

Wilson, E., Kenny, A., \& Dickson-Swift, V. (2018). Ethical challenges in community-based participatory research: A scoping review. Qualitative Health Research, 28(2), 189-199. https://doi.org/10.1177/1049732317690721

\footnotetext{
About the Authors

Jill Juris is an assistant professor of Recreation Management in the Beaver College of Health Sciences at Appalachian State University (Boone, NC, USA).

Rachel Scrivano is a doctoral student in Social Work at The Ohio State University (Columbus, OH, USA).

Elizabeth Speidel is a seminary student specializing in Chaplaincy and Ecology \& Justice at Methodist Theological School of Ohio (Columbus, OH, USA).

Lauren Bailey is a Master of Social Work graduate from The Ohio State University (Washington, DC, USA).

Shannon Jarrott is a professor of Social Work at The Ohio State University (Columbus, OH, USA).

Correspondence concerning this article should be addressed to Jill Juris Naar at naarjj@appstate.edu.
} 